\title{
Aspirin induced adverse skin reactions: new pathophysiological aspects
}

\author{
Bettina Wedi, Alexander Kapp
}

Clinically, aspirin induced adverse skin reactions resemble true immunologically mediated allergic reactions. However, it is well accepted that aspirin intolerance is not mediated by specific IgE antibodies. The exact mechanisms involved are far from clear ${ }^{12}$ and therefore no reliable diagnostic in vitro tests exist, and risky and time consuming provocation tests are regarded as the diagnostic gold standard. Most studies of pathophysiological mechanisms deal with nasal polyps or asthma. However, compared with asthma and nasal polyps, aspirin intolerance is very common in chronic urticaria..$^{3-7}$ The reason for the preferred organ manifestation is unknown.

Several lines of evidence point to a potent disturbance in the eicosanoid balance (cyclooxygenase theory) resulting in a shift towards increased production of leukotrienes. ${ }^{8-12}$

Our previous studies have shown that aspirin induced adverse skin reactions proved by positive oral provocation tests are common in chronic urticaria ${ }^{13}$ and can be characterised by enhanced sulfidoleukotriene production in IL-3 primed leucocyte suspensions after stimulation with $\mathrm{C} 5 \mathrm{a} .{ }^{14}{ }^{15}$ This study was undertaken to define the rate of positive oral challenge tests in patients with chronic urticaria and a history of adverse skin reactions to aspirin. We also wanted to investigate the sensitivity and specificity of enhanced sulfidoleukotriene production induced by different basophil agonists for the diagnosis of aspirin intolerance.

\section{Methods \\ PATIENTS \\ EDTA anticoagulated blood from 84 patients with chronic urticaria and suspected worsening of urticarial eruptions after intake of aspirin was analysed before oral provocation tests. To define an atopic diathesis total IgE (CAP IgE FEIA, Pharmacia-Biotech, Freiburg, Ger- many) and Sx1 Phadiatop (RAST atopy screening test for seven common allergens; CAP IgE-FEIA, Pharmacia-Biotech, Freiburg, Germany) were assessed.}

Department of
Dermatology and
Allergology, Hannover
Medical University,
D-30449 Hannover,
Germany
B Wedi
A Kapp
Correspondence to:
Dr A Kapp
Bettina_Wedi@online.edu

ORAL PROVOCATION TEST

Asymptomatic patients were given increasing doses of aspirin in gelatine capsules as inpatients under single blind, placebo controlled conditions. The following increasing doses of aspirin were used: $50 \mathrm{mg}, 100 \mathrm{mg}, 250 \mathrm{mg}$, $500 \mathrm{mg}, 1000 \mathrm{mg}$ (cumulative dose $1900 \mathrm{mg}$ ). Provocation tests were considered positive when objective symptoms such as urticarial eruptions, bronchial asthma, angio-oedema, or anaphylactoid reactions were observed.
RELEASE OF SULFIDOLEUKOTRIENES FROM LEUCOCYTE SUSPENSIONS

Leucocyte suspensions were isolated by dextran sedimentation and analysed for de novo production of $\mathrm{LTC}_{4}, \mathrm{LTD}_{4}$, and $\mathrm{LTE}_{4}$ with a commercially available ELISA (cellular antigen stimulation test (CAST); DPC Biermann, Bad Nauheim, Germany). Leucocyte suspensions were pre-incubated with interleukin (IL)-3 $(10 \mathrm{ng} / \mathrm{ml})$ for 15 minutes at $37^{\circ} \mathrm{C}$. The cells were then stimulated with $\mathrm{C} 5 \mathrm{a}\left(10^{-7} \mathrm{M}\right)$, platelet activating factor (PAF; $10^{-5} \mathrm{M}$ ), and f-MetLeu-Phe (fMLP; $10^{-6} \mathrm{M}$ ) for 30 minutes at $37^{\circ} \mathrm{C}$. Previous experiments have shown that these concentrations of mediators gave optimal results. Our previous results also showed that stimulation with aspirin could be omitted. ${ }^{14}$ In accordance with the instructions of the manufacturer of the SLT-ELISA, anti-FceRI-mAb (22E7) was used as a positive control and the IL-3 containing stimulation buffer served as a negative control. The sulfidoleukotriene values obtained with the stimulation buffer were subtracted regularly.

\section{STATISTICAL METHODS}

The sensitivity and specificity of the in vitro assay were compared with the results obtained from oral provocation tests using a $2 \times 2$ contingency table. The following pairs are possible: $+/+=\mathrm{a},-/-=\mathrm{d},+/-=\mathrm{c}$, and $-/+=\mathrm{b}$. Sensitivity was $100 \times \mathrm{a} /(\mathrm{a}+\mathrm{c})$, specificity was $100 \times d /(b+d)$. The following cut off points (after subtraction of IL-3 containing stimulation buffer control) were used: $300 \mathrm{pg} / \mathrm{ml}$ for C5a, $150 \mathrm{pg} / \mathrm{ml}$ for both PAF and fMLP. Statistical significance of the data was assessed by the Mann-Whitney rank sum test or $\chi$ test with $\alpha=0.05$ using a statistical software package (SigmaStat for Windows, Jantel Scientific, Erkrath, Germany).

\section{Results}

ORAL PROVOCATION TESTS WITH ASPIRIN

Of 84 patients with a clear history of aspirin induced adverse skin reactions (urticaria and/or angio-oedema) only $21 \%$ had positive clinical reactions to oral provocation with aspirin. No cross reactivity to acetaminophen (paracetamol) was found; $78 \%$ of the pseudoallergic patients were women and 39\% were atopic compared with $53 \%$ and $49 \%$, respectively, among the aspirin tolerant patients.

DE NOVO PRODUCTION OF SULFIDOLEUKOTRIENES IN LEUCOCYTE SUSPENSIONS

Patients with positive oral provocation tests to aspirin had significantly higher levels of de novo sulfidoleukotriene production than subjects with negative oral provocation tests after 
Table 1 De novo production of sulfidoleukotrienes (SLT) in patients with positive and negative oral provocation test (OPT) to aspirin

\begin{tabular}{lll}
\hline & \multicolumn{2}{l}{$S L T(p g / m l)$} \\
\cline { 2 - 3 } & OPT positive & OPT negative \\
\hline C5a $\left(10^{-7} \mathrm{M}\right)$ & $\mathrm{n}=18$ & $\mathrm{n}=66$ \\
Mean & 692 & 117 \\
Median & 583 & 79 \\
Min-max & $45-2010$ & $0-549$ \\
& $\mathrm{p}<0.0001$ & \\
PAF $\left(10^{-5} \mathrm{M}\right)$ & $\mathrm{n}=8$ & $\mathrm{n}=32$ \\
Mean & 371 & 56 \\
Median & 300 & 45 \\
Min-max & $141-647$ & $0-198$ \\
& $\mathrm{p}<0.0001$ & $\mathrm{n}=32$ \\
fMLP $\left(10^{-6} \mathrm{M}\right)$ & $\mathrm{n}=8$ & 123 \\
Mean & 444 & 84 \\
Median & 582 & $0-647$ \\
Min-max & $11-848$ & \\
& $\mathrm{p}<0.01$ & \\
\hline
\end{tabular}

PAF = platelet activating factor; fMLP $=$ f-Met-Leu-Phe.

* Randomly selected patients with a history of adverse skin reaction to aspirin.

stimulation with C5a, PAF, and fMLP (table 1). There was no correlation between sulfidoleukotriene production and total serum $\operatorname{IgE}$ and/or the detection of specific IgE antibodies. Total serum IgE levels of aspirin tolerant and intolerant subjects did not show any significant difference. Moreover, C5a, PAF, or fMLP induced sulfidoleukotriene release did not correlate with results obtained with anti-FceRI as stimulating agent.

SENSITIVITY AND SPECIFICITY OF DE NOVO SULFIDOLEUKOTRIENE PRODUCTION FOR ASPIRIN INTOLERANCE

Sensitivity and specificity of stimulated sulfidoleukotriene production in IL-3 primed leucocyte suspensions were $83 \%$ and $94 \%$ for C5a (cut off $300 \mathrm{pg} / \mathrm{ml}$ ), $88 \%$ and $94 \%$ for PAF (cut off $150 \mathrm{pg} / \mathrm{ml}$ ), and $63 \%$ and $81 \%$ for fMLP (cut off $150 \mathrm{pg} / \mathrm{ml}$ ), respectively. Using identical cut off values, the sensitivity and specificity increased to $88 \%$ and $91 \%$ when two stimuli were positive. In the case of increased sulfidoleukotriene production to all three basophil agonists (C5a, PAF, and fMLP), sensitivity decreased to $50 \%$ while specificity reached $100 \%$.

\section{Discussion}

Our data clearly show that it is not possible to diagnose aspirin induced adverse skin reactions reliably on history alone since only $21 \%$ of patients with a clear cut history of provoked skin eruptions had positive oral provocation tests. This result agrees with published data on aspirin induced asthma. ${ }^{316}$ Women were particularly affected by aspirin induced adverse skin reactions, and atopy or total serum $\operatorname{IgE}$ levels were not associated.

It was shown that the incomplete basophil agonists $\mathrm{C} 5 \mathrm{a}, \mathrm{PAF}$, and $\mathrm{fMLP}$ resulted in a significantly higher production of sulfidoleukotrienes in subjects with aspirin intolerance than in aspirin tolerant subjects. Furthermore, we found that C5a, PAF, and fMLP induced sulfidoleukotriene release represents a sensitive and specific diagnostic tool for pseudoallergy to aspirin. These data therefore support the hypothesis that a shift in the eicosanoid balance towards higher leukotriene production may play a major pathophysiological role, not only in aspirin induced asthma, but also in aspirin induced adverse skin reactions.

Taken together, our data indicate that pseudoallergic reactions to aspirin are characterised by an enhanced susceptibility of basophils to incomplete agonists such as $\mathrm{C} 5 \mathrm{a}, \mathrm{PAF}$, and fMLP, resulting in a significant production of sulfidoleukotrienes which may be responsible for mediating the inflammatory skin response in a group of aspirin sensitive patients.

1 Corominas M. Mechanisms implicated in adverse reactions to non-steroidal anti-inflammatory drugs. Clin Exp Allergy 1998;28:41-5

2 Stevenson DD. Proposed mechanisms of aspirin sensitivity reactions. F Allergy Clin Immunol 1987;80:788-90.

3 Kalyoncu AF, Karakaya G, Sahin AA, et al. Occurrence of allergic conditions in asthmatics with analgesic intolerance. fllergic conditions in asthmol 1999;54:428-35.

4 Settipane GA. Aspirin sensitivity and allergy. Biomed Pharmacother 1988;42:493-8.

5 Chafee FH, Settipane GA. Aspirin intolerance. I. Frequency in an allergic population. $\mathcal{F}$ Allergy Clin Immunol 1974;53: 193-9.

6 Settipane GA, Chafee FH, Klein DE. Aspirin intolerance. II. A prospective study in an atopic and normal population. f Allergy Clin Immunol 1974;53:200-4.

7 Hosemann WG, Baenkler HW, Günther F. ASA-induced release of histamine from nasal mucous membranes in anagesic intolerance and polyposis nasi. Rhinology 1990;28: 231-8.

8 Cowburn AS, Sladek K, Soja J, et al. Overexpression of leukotriene $\mathrm{C} 4$ synthase in bronchial biopsies from patients with aspirin-intolerant asthma. F Clin Invest 1998;101:83446.

Sampson AP, Cowburn AS, Sladek K, et al. Profound overexpression of leukotriene C4 synthase in bronchial biopsies from aspirin-intolerant asthmatic patients. Int Arch Allergy Appl Immunol 1997;113:355-7.

10 Szczeklik A. Mechanism of aspirin-induced asthma. $f$ Immunol 1997;52:613-9.

11 Szczeklik A, Sladek K, Dworski R, et al. Bronchial aspirin challenge causes specific eicosanoid response in aspirinsensitive asthmatics. Am F Respir Crit Care Med 1996;154: 1608-14.

12 Szczeklik A. The cyclooxygenase theory of aspirin-induced asthma. Eur Respir F 1990;3:588-93.

13 Wedi B, Wagner S, Werfel T, et al. Prevalence of Helicobacter pylori associated gastritis in chronic urticaria. Int Arch Allergy Immunol 1998;116:288-94.

14 Wedi B, Elsner J, Kapp A. In vitro diagnostic of pseudoallergic reactions: new aspects. Allergy Clin Immunol Intern gic reactions:

15 Czech W, Schopf E, Kapp A. Release of sulfidoleukotrienes in vitro: its relevance in the diagnosis of pseudoallergy to acetylsalicylic acid. Inflamm Res 1995;44:291-5.

16 Bochenek G, Nizankowska E, Szczeklik A. The atopy trait in hypersensitivity to nonsteroidal anti-inflammatory drugs. $\mathcal{F}$ Immunol 1996;51:16-23. 